\title{
BMJ Open Modeling lifetime costs and health outcomes attributable to secondhand smoke exposure at home among Korean adult women
}

\author{
Jiyae Lee, ${ }^{1}$ Ah Ram Han, ${ }^{1}$ Dalwoong Choi, ${ }^{2}$ Kyung-Min Lim, ${ }^{1}$ SeungJin Bae ${ }^{1}$
}

To cite: Lee J, Han AR, Choi $\mathrm{D}$, et al. Modeling lifetime costs and health outcomes attributable to secondhand smoke exposure at home among Korean adult women. BMJ Open 2017;0:e013292. doi:10.1136/ bmjopen-2016-013292

- Prepublication history and additional material for this paper are available online. To view these files please visit the journal online (http://dx.doi. org/10.1136/bmjopen-2016013292).

Received 5 July 2016 Revised 14 February 2017 Accepted 9 March 2017

CrossMark

${ }^{1}$ College of Pharmacy, Ewha Womans University, Seoul, Republic of Korea

${ }^{2}$ Department of Public Health Science, Graduate School, Korea University, Seoul, Republic of Korea

Correspondence to Dr SeungJin Bae; sjbae@ewha.ac.kr

\section{ABSTRACT}

Purpose The aim of this research is to estimate lifetime costs and health consequences for Korean adult women who were exposed to secondhand smoke (SHS) at home. Methods A Markov model was developed to project the lifetime healthcare costs and health outcomes of a hypothetical cohort of Korean women who are 40 years old and were married to current smokers. The Korean epidemiological data were used to reflect the natural history of SHS-exposed and non-exposed women. The direct healthcare costs (in 2014 US dollars) and qualityadjusted life years (QALYs) were annually discounted at $5 \%$ to reflect time preference. The time horizon of the analysis was lifetime and the cycle length was 1 year. Deterministic and probabilistic sensitivity analyses were conducted.

Results In the absence of SHS exposure, Korean women will live 41.32 years or 34.56 QALYs before discount, which corresponded to 17.29 years or 15.35 QALYS after discount. The SHS-exposed women were predicted to live 37.91 years and 31.08 QALYs before discount and 16.76 years and 14.62 QALYs after discount. The estimated lifetime healthcare cost per woman in the SHS non-exposed group was US\$11214 before the discount and US\$2465 after discount. The negative impact of SHS exposure on health outcomes and healthcare costs escalated as the time horizon increased, suggesting that the adverse impact of SHS exposure may have higher impact on the later part of the lifetime. The result was consistent across a wide range of assumptions.

Conclusion Life expectancy might underestimate the impact of SHS exposure on health outcomes, especially if the time horizon of the analysis is not long enough. Early intervention on smoking behaviour could substantially reduce direct healthcare costs and improve quality of life attributable to SHS exposure.

\section{INTRODUCTION}

Nearly 6 million people are killed by tobacco annually, and more than 600000 of these are non-smokers exposed to the secondhand smoke (SHS) or environmental tobacco smoke. ${ }^{2}$ Non-smokers in workplace or households are forced to be exposed to SHS, yet SHS in workplace is becoming less of an issue in many developed countries, thanks to several smoke-free laws that have banned

\section{Strengths and limitations of this study}

- Our study is the first attempt to project health and economic outcomes attributable to secondhand smoking (SHS) using a Markov simulation model.

- The model was validated by comparing its output against a population-based cohort study and the robustness of the assumptions was tested by conducting deterministic and probabilistic sensitivity analyses.

- Our results should be interpreted with caution, since they hinge on several assumptions due to insufficient and inconsistent data. Future research on the long-term impact of SHS should be followed.

smoking in large buildings and restaurants. ${ }^{34}$ However, few policies have been aggressive enough to ban smoking at home, leaving non-smokers in households exposed to SHS. Yet, exposure tonicotine and cotinine concentrations in urine were significantly higher among SHS at home than among SHS at work, suggesting that SHS at home could cause significant health concerns. ${ }^{56}$ SHS at home is of special concern in Korea, where the gender gap in smoking is especially high; only $4.3 \%$ of Korean adult women are smokers and $36.2 \%$ of Korean men are smokers as of 2013, whereas the Organisation for Economic Co-operation and Development (OECD) reported that the average percentage of men and women smokers are $24.2 \%$ and $15.5 \%$, respectively. ${ }^{1}$

Several studies have reported that SHS exposure is associated with diverse health conditions, such as lung cancer, coronary heart disease and respiratory disease in adults and sudden infant death syndrome. ${ }^{7-9}$ Increased morbidity and mortality result in increased healthcare costs among non-smokers exposed to SHS, which occurs over a lifetime. However, few studies have estimated the lifetime cost or expected health outcomes such 


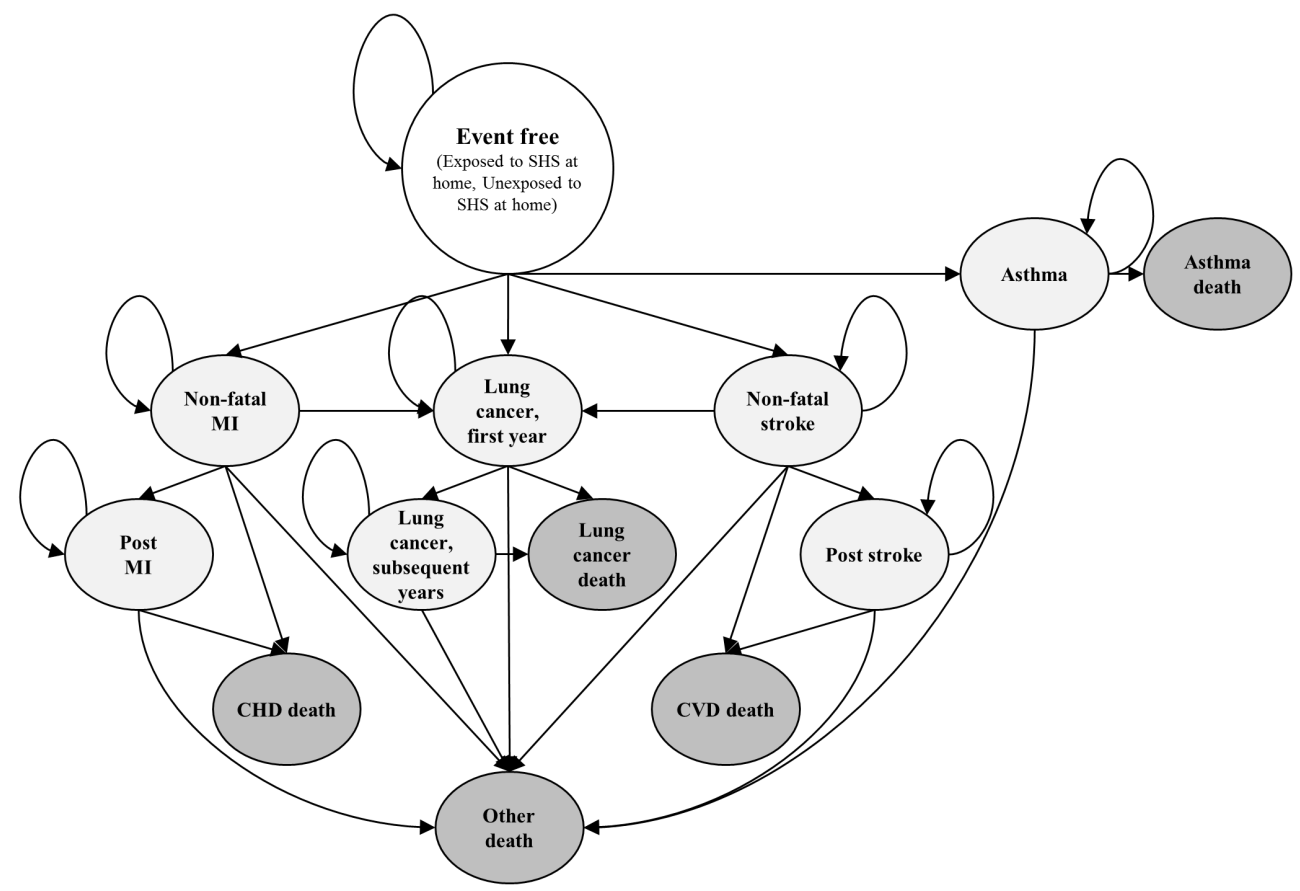

Figure 1 Health states and disease progression for Korean adult women who are exposed to SHS at home. CHD, coronary heart disease; CVD, cardiovascular disease; MI, myocardial infarction; SHS, secondhand smoke.

as quality-adjusted life years (QALYs) attributable to SHS, much less in Asian countries where SHS exposure among women is especially high. ${ }^{1}$ Most studies have calculated the annual cost of SHS, ${ }^{3}{ }^{410}$ and several studies have estimated the cost attributable to smoking using a simulation model, yet they focused on the smokers, not the non-smokers exposed to SHS. ${ }^{11-14}$ Several studies have conducted a cost-effectiveness analysis of smoking cessation drugs ${ }^{1516}$ yet those studies focused on the impact of smoking cessation drugs among smokers, and the SHS-exposed individuals were not considered in those studies.

The purpose of this study was to estimate health and economic outcomes of the lifetime cost of SHS at home among adult Korean women. More specifically, we sought to evaluate the direct healthcare cost and QALYs attributable to SHS among Korean adult women who are highly vulnerable to the SHS exposure at home.

\section{METHODS}

\section{Overview}

A Markov model, the secondhand smoking exposure outcome model (SHE model, figure 1), was developed to project the economic and health outcomes associated with SHS at home among adult Korean women in their lifetime; more specifically, we compared the cost (in US dollars) and QALYs for the SHS-exposed group with the SHS non-exposed group. The target population of the model was women aged 40 years old and who were married to current smokers, because the increased risk associated with SHS exposure was observed among middle-aged housewives. ${ }^{17} 18$ Our focus was on the direct medical costs attributable to SHS exposure; indirect or non-medical costs such as productivity costs and travel costs were not included in our analysis. ${ }^{19} 20$ To capture the long-term impact of SHS exposure, the time horizon of the model was lifetime ${ }^{21}$ and the cycle length was set to 1 year, based on previous studies. ${ }^{14}{ }^{15}$ Due to data limitation, we focused on the SHS caused by current smokers, which made our projections rather conservative. TreeAge Pro 2015 Software was used to incorporate estimates from various literatures and build the mathematical simulation model. All future costs and outcomes were discounted to reflect people's positive time preference, namely, people prefer to receive benefits sooner than later, thus discounting adjusts the time preference by undervaluing future benefits to reflect the present value. ${ }^{20}$ Both costs and health benefits were annually discounted at $5 \%$ based on economic evaluation guidelines, ${ }^{20}{ }^{22}$ and publicly funded healthcare perspective was taken.

\section{The economic model}

A Markov state-transition simulation model was built to simulate the natural history of exposure to $\mathrm{SHS}^{23}$ for the SHS-exposed and SHS non-exposed groups based on epidemiological data. A defined set of health states and the transitions through them described the natural history of the disease (SHS exposure). Patients were assigned to a single health state at any given time, which was mutually exclusive and collectively exhaustive in terms of SHS disease characteristics. ${ }^{24}$

To identify clinical conditions that influence the cost and health outcomes of the SHS-exposed individuals at a statistically significant level, we reviewed previously published epidemiological and cost studies 
and four conditions (lung cancer, myocardial infarction (MI), stroke and asthma) were included in the SHE model. ${ }^{4} 1017$ 25-29 We considered four major health outcomes based on previous systematic reviews and official recommendations ${ }^{9} 262830$ and conditions whose causal association was inconclusive (such as breast cancer, chronic obstructive pulmonary disease (COPD), cervical cancer) were not included. ${ }^{930}$

Health conditions that were reported to trigger an elevated risk among SHS-exposed women but whose influence was inconsistent or failed to reach a statistically significant level were not considered in our analysis. ${ }^{3233}$ The model was progressive in nature; namely, once a patient developed a severe condition, such as lung cancer, the patients could not move into a milder condition such as asthma. ${ }^{16}$ Thus, individuals in the event-free state can move to asthma, and patients in asthma cannot move back to the event-free state. Of those four conditions, three conditions (lung cancer, MI and stroke) were further categorised as first year in event health state (such as stroke) and subsequent health states (eg, poststroke), because the cost of treating the health conditions and transition probabilities in the first year and following years differ significantly ${ }^{34-36}$ (figure 1 ). The model cycled annually until all individuals had moved to fatal states (died) or became 100 years old, at which point all of them were assumed to be dead. ${ }^{24}$

\section{Target population}

We analysed a cohort of 10000 married non-smoking Korean women aged 40 years old at the time of the simulation and whose husbands currently smoked 1 to 19 cigarettes a day because most studies on passive smoking focused on middle-aged women, and those studies defined current smokers as such. ${ }^{171825}$ Our target population criterion is consistent with the habit of Korean male smokers because Korean male smokers consume 15.5 cigarettes per day on average. ${ }^{37}$ We assumed that those women had been exposed to SHS at home since marriage, which translate into roughly 10 years of exposure.

\section{Input data}

Table 1 shows the input data used in the model with their respective references. Domestic cost and epidemiological data with large sample sizes were preferably sourced; foreign data were referenced when domestic data were not available. More specifically, the natural history of women non-exposed to SHS was estimated from domestic epidemiological studies ${ }^{38-40}$ except for asthma, for which domestic data were not available, ${ }^{41}$ and the transition probabilities of the four conditions among SHS-exposed women were estimated using relative risk reported from published literature. ${ }^{1725-28}$

\section{Relative risk}

To quantify the increased risk associated with the exposure to SHS, we referred to previous studies, focusing on meta-analyses or systematic reviews among passive smokers. Cohort or case-control studies with large sample sizes were also considered if few studies were available. A limited number of domestic studies were found, with Jee and colleagues' study on the effect of husbands' smoking on the incidence of lung cancer among 160130 Korean women aged $40-88$ being the only domestic study identified by the authors. ${ }^{25}$ Jee and colleagues reported that wives of current smokers were two times more likely

Table 1 Annual incidence/mortality rate per disease state of Korean adult female population who are not exposed to SHS and the relative risk of morbidity and mortality related with SHS exposure used in the model

\begin{tabular}{|c|c|c|c|c|c|c|c|}
\hline \multirow[b]{2}{*}{ Disease states } & \multicolumn{5}{|c|}{ Age-specific incidence/mortality rate of Korean women } & \multicolumn{2}{|l|}{ Relative risk } \\
\hline & 40-49 & $50-59$ & $60-69$ & 70 and above & Reference & Point estimate $(95 \% \mathrm{Cl})$ & References \\
\hline \multicolumn{8}{|l|}{ Lung cancer } \\
\hline Mortality† & $21.09 \%$ & $21.09 \%$ & $21.09 \%$ & $21.09 \%$ & 37 & 1.31 (1.16 to 1.48$)$ & 28 \\
\hline \multicolumn{8}{|c|}{ Myocardial infarction } \\
\hline Mortality $\ddagger$ & $15.54 \%$ & $12.19 \%$ & $14.60 \%$ & $28.92 \%$ & 36 & $1.22(1.14$ to 1.30$)$ & 17 \\
\hline \multicolumn{8}{|l|}{ Stroke } \\
\hline Incidence* & $0.06 \%$ & $0.20 \%$ & $0.52 \%$ & $1.47 \%$ & 36 & 1.32 (1.14 to 1.53$)$ & 27 \\
\hline Mortality§ & $16.34 \%$ & $8.23 \%$ & $10.81 \%$ & $27.00 \%$ & 36 & 1.23 (1.07 to 1.40$)$ & 27 \\
\hline \multicolumn{8}{|l|}{ Asthma } \\
\hline
\end{tabular}

*Incidence rates among event-free individuals.

†Mortality rate among patients with lung cancer.

¥Mortality rates among patients with myocardial infarction.

$\S$ Mortality rates among patients who had a stroke.

१Mortality rates among patients with asthma. 
Table 2 Annual secondhand smoke-related morbidity costs (in 2014 US dollars) and utility used in the model

\begin{tabular}{|c|c|c|c|c|c|c|c|}
\hline \multirow[b]{2}{*}{ Disease states/age } & \multicolumn{3}{|c|}{ Annual healthcare costs } & \multicolumn{4}{|l|}{ Utility } \\
\hline & First year & $\begin{array}{l}\text { Subsequent } \\
\text { years }\end{array}$ & Reference & First year & & $\begin{array}{l}\text { Subsequent } \\
\text { years }\end{array}$ & Reference \\
\hline Lung cancer & 20772 & 6584 & 32 & 0.61 & & 0.50 & 45 \\
\hline Myocardial infarction & 7486 & 1232 & 33 & & 0.80 & & 44 \\
\hline Stroke & 7735 & 1003 & 33 & & 0.58 & & 44 \\
\hline Asthma & & & 40 & & 0.82 & & 44 \\
\hline
\end{tabular}

to have lung cancer compared with their non-SHS-exposed counterparts, and the increased risk was statistically significant at 0.05 level. Because Jee and colleagues' study definition of a current smoker (those who consume 1 to 19 cigarettes per day) is in line with the average number of daily cigarettes consumed by Korean male smokers, that is, $15.5,{ }^{37}$ we referred to the study. The increased risk of morbidity and mortality among the SHS-exposed group of other diseases (asthma, stroke and MI) was estimated from non-Korean populations due to data availability, ${ }^{17} 26-28$ and the increased risk associated with SHS exposure was assumed to be constant across the age group (table 1).

\section{Costs}

Our study included direct medical costs attributable to SHS exposure. Costs of health states (first year and subsequent year) were based on cost data estimated from the Korean National Health Insurance database. ${ }^{34} 3542$ The macro costing approach was employed, ${ }^{43}$ and direct non-medical costs, such as transportation costs, were not included in our analysis. Costs were adjusted by the medical care component of the Consumer Price Index in Korea ${ }^{44}$ and then adjusted to 2014 US dollars; US $\$ 1$ equals 1053.22 Korean won as of $2014 .{ }^{45}$ The annual direct costs in 2014 US dollars are summarised in table 2.

\section{Quality-adjusted life year}

To quantify the impact of SHS exposure on the health-related quality of life, we considered QALY, which incorporates life expectancy as well as the health-related quality of life. ${ }^{20}$ The age-specific and sex-specific quality-of-life weights of the Korean general population were sourced from a national study that used EQ-5D, ${ }^{37}$ and the utility of SHS-exposed women who were event free was assumed to be the same as that of age-matched SHS non-exposed women who were event free. The utilities corresponding to specific health states, as shown in table 2, were obtained from a Korean catalogue of EQ-5D utility weights for chronic diseases. ${ }^{46}$ For the utility of lung cancer, no domestic study was identified; thus, we referred to an Italian study that estimated the utility of lung cancer based on 95 patients using EQ-5D. ${ }^{47}$

\section{Sensitivity analysis}

Because our projection was based on several assumptions, we conducted sensitivity analyses to investigate the robustness of the assumptions. For the univariate sensitivity analysis (where a single variable is varied over plausible ranges), we explored the impact of varied relative risk $(95 \% \mathrm{CI})$, discount rate $(0 \%, 3 \%, 7.5 \%)$, time horizon (5 years, 10 years and 20 years), utilities $(95 \%$ CI) and annual cost (95\% CI) on the economic and health outcomes (table 3 ). For the probabilistic sensitivity analyses, second-order Monte Carlo simulations were performed 10000 times and visually presented in online supplementary figure 1 . We employed a gamma distribution for cost, a log-normal distribution for relative risk and a beta distribution for utilities. ${ }^{48}$ The results are visually presented as a scatterplot.

\section{RESULTS}

The SHE model predicted that in the absence of SHS exposure, Korean women will live 41.32 years and 34.56 QALYs before discount, which corresponded to 17.29 years and 15.35 QALYs after the $5 \%$ discount. The SHS-exposed women were predicted to live 37.91 years and 31.08 QALYs before discount and 16.76 years and 14.62 QALYs after the $5 \%$ discount (table 3), suggesting that the negative impact of SHS exposure on the quality of life was greater than its impact on life expectancy regardless of the discount rate. The result also implied that SHS exposure was more associated with morbidity than mortality. Figure 2 illustrates that the life expectancy in the two groups was almost the same until they turned 75 years old, and the QALY curves from two groups diverged about 20 years earlier. As shown in table 3, the negative influence of SHS on health outcomes was mitigated as the discount rate increased (from $-8.3 \%$ to $-1.7 \%$ for life expectancy and from $-10.1 \%$ to $-3.4 \%$ for QALYs) or time horizon became shorter (from $-0.2 \%$ to $-0.0 \%$ for life expectancy and from $-1.9 \%$ to $-0.5 \%$ for QALYs), suggesting that the adverse impact of SHS exposure on health outcomes was more likely to occur during the later part of the time horizon.

The estimated lifetime healthcare cost per woman in the SHS non-exposed group was US $\$ 11214$ before the discount and US $\$ 2465$ after discount, whereas US\$11 854 and US $\$ 3065$ for SHS-exposed women before and after discount, respectively. The negative economic impact of SHS exposure escalated as the time horizon increased (from US $\$ 64$ for 5 years to US $\$ 472$ for 20 years, since the projected value for 20 years is more than four times 
Table 3 Base-case and one-way sensitivity analyses for Korean adult women who are exposed to secondhand smoke (SHS) at home compared with women not exposed

\begin{tabular}{|c|c|c|c|c|c|c|c|}
\hline \multirow[b]{2}{*}{ Parameters } & \multirow{2}{*}{$\begin{array}{l}\text { SHS exposure } \\
\text { states }\end{array}$} & \multicolumn{2}{|c|}{$\begin{array}{l}\text { Direct healthcare costs } \\
\text { (US dollars) }\end{array}$} & \multicolumn{2}{|c|}{$\begin{array}{l}\text { Life expectancy } \\
\text { (years) }\end{array}$} & \multicolumn{2}{|c|}{ Quality-adjusted life years } \\
\hline & & Total & Incremental (\%) & Total & Incremental (\%) & Total & Incremental (\%) \\
\hline \multicolumn{8}{|l|}{ Base-case } \\
\hline & No & 2465 & - & 17.29 & - & 15.35 & - \\
\hline & Yes & 3065 & $600(24.3 \%)$ & 16.76 & $-0.53(-3.1 \%)$ & 14.62 & $-0.73(-4.8 \%)$ \\
\hline \multicolumn{8}{|l|}{ Discount rate } \\
\hline \multirow[t]{2}{*}{$0 \%$} & No & 11214 & - & 41.32 & - & 34.56 & - \\
\hline & Yes & 11854 & $640(5.7 \%)$ & 37.91 & $-3.41(-8.3 \%)$ & 31.08 & $-3.48(-10.1 \%)$ \\
\hline \multirow[t]{2}{*}{$3 \%$} & No & 4298 & - & 23.28 & - & 20.26 & - \\
\hline & Yes & 5012 & $714(16.6 \%)$ & 22.20 & $-1.08(-4.6 \%)$ & 18.96 & $-1.30(-6.4 \%)$ \\
\hline \multirow[t]{2}{*}{$7.5 \%$} & No & 1348 & - & 12.81 & - & 11.60 & - \\
\hline & Yes & 1804 & $456(33.8 \%)$ & 12.59 & $-0.22(-1.7 \%)$ & 11.20 & $-0.40(-3.4 \%)$ \\
\hline \multicolumn{8}{|l|}{ Time horizon } \\
\hline \multirow[t]{2}{*}{5 years } & No & 82 & - & 4.43 & - & 4.23 & - \\
\hline & Yes & 146 & $64(78.0 \%)$ & 4.43 & $-0.00(0.0 \%)$ & 4.21 & $-0.02(-0.5 \%)$ \\
\hline \multirow[t]{2}{*}{10 years } & No & 231 & - & 7.88 & - & 7.45 & - \\
\hline & Yes & 417 & $186(80.5 \%)$ & 7.87 & $-0.01(-0.1 \%)$ & 7.37 & $-0.08(-1.1 \%)$ \\
\hline \multirow[t]{2}{*}{20 years } & No & 706 & - & 12.62 & - & 11.71 & - \\
\hline & Yes & 1178 & $472(66.9 \%)$ & 12.60 & $-0.02(-0.2 \%)$ & 11.49 & $-0.22(-1.9 \%)$ \\
\hline \multicolumn{8}{|c|}{ Relative risk of lung cancer morbidity } \\
\hline \multirow{2}{*}{$\begin{array}{l}\text { Upper bound of } \\
95 \% \mathrm{Cl}\end{array}$} & No & 2465 & - & 17.29 & - & 15.35 & - \\
\hline & Yes & 3596 & $1131(45.9 \%)$ & 16.65 & $-0.64(-3.7 \%)$ & 14.52 & $-0.83(-5.4 \%)$ \\
\hline \multirow{2}{*}{$\begin{array}{l}\text { Lower bound of } \\
95 \% \mathrm{Cl}\end{array}$} & No & 2465 & - & 17.29 & - & 15.35 & - \\
\hline & Yes & 2806 & $341(13.8 \%)$ & 16.81 & $-0.48(-2.8 \%)$ & 14.66 & $-0.69(-4.5 \%)$ \\
\hline \multicolumn{8}{|c|}{ Relative risk of lung cancer mortality } \\
\hline \multirow{2}{*}{$\begin{array}{l}\text { Upper bound of } \\
95 \% \mathrm{Cl}\end{array}$} & No & 2465 & - & 17.29 & - & 15.35 & - \\
\hline & Yes & 3053 & $588(23.9 \%)$ & 16.75 & $-0.54(-3.1 \%)$ & 14.61 & $-0.74(-4.8 \%)$ \\
\hline \multirow{2}{*}{$\begin{array}{l}\text { Lower bound of } \\
95 \% \mathrm{Cl}\end{array}$} & No & 2465 & - & 17.29 & - & 15.35 & - \\
\hline & Yes & 3079 & $614(24.9 \%)$ & 16.77 & $-0.52(-3.0 \%)$ & 14.62 & $-0.73(-4.8 \%)$ \\
\hline \multicolumn{8}{|c|}{ Relative risk of myocardial infarction morbidity } \\
\hline \multirow{2}{*}{$\begin{array}{l}\text { Upper bound of } \\
95 \% \mathrm{Cl}\end{array}$} & No & 2465 & - & 17.29 & - & 15.35 & - \\
\hline & Yes & 3194 & $729(29.6 \%)$ & 16.75 & $-0.54(-3.1 \%)$ & 14.60 & $-0.75(-4.9 \%)$ \\
\hline \multirow{2}{*}{$\begin{array}{l}\text { Lower bound of } \\
95 \% \mathrm{Cl}\end{array}$} & No & 2465 & - & 17.29 & - & 15.35 & - \\
\hline & Yes & 2966 & $501(20.3 \%)$ & 16.77 & $-0.52(-3.0 \%)$ & 14.63 & $-0.72(-4.7 \%)$ \\
\hline Relative risk of corc & nary heart diseas & e mortali & & & & & \\
\hline Upper bound of & No & 2465 & - & 17.29 & - & 15.35 & - \\
\hline $95 \% \mathrm{Cl}$ & Yes & 3059 & $594(24.1 \%)$ & 16.76 & $-0.53(-3.1 \%)$ & 14.61 & $-0.74(-4.8 \%)$ \\
\hline Lower bound of & No & 2465 & - & 17.29 & - & 15.35 & - \\
\hline $95 \% \mathrm{Cl}$ & Yes & 3071 & 606 (24.6\%) & 16.77 & $-0.52(-3.0 \%)$ & 14.62 & $-0.73(-4.8 \%)$ \\
\hline Relative risk of stro & ke morbidity & & & & & & \\
\hline Upper bound of & No & 2465 & - & 17.29 & - & 15.35 & - \\
\hline $95 \% \mathrm{Cl}$ & Yes & 3243 & 778 (31.6\%) & 16.75 & $-0.54(-3.1 \%)$ & 14.58 & $-0.77(-5.0 \%)$ \\
\hline Lower bound of & No & 2465 & - & 17.29 & - & 15.35 & - \\
\hline $95 \% \mathrm{Cl}$ & Yes & 2913 & 448 (18.2\%) & 16.77 & $-0.52(-3.0 \%)$ & 14.65 & $-0.70(-4.6 \%)$ \\
\hline
\end{tabular}


Table 3 Continued

\begin{tabular}{|c|c|c|c|c|c|c|c|}
\hline \multirow[b]{2}{*}{ Parameters } & \multirow{2}{*}{$\begin{array}{l}\text { SHS exposure } \\
\text { states }\end{array}$} & \multicolumn{2}{|c|}{$\begin{array}{l}\text { Direct healthcare costs } \\
\text { (US dollars) }\end{array}$} & \multicolumn{2}{|c|}{$\begin{array}{l}\text { Life expectancy } \\
\text { (years) }\end{array}$} & \multicolumn{2}{|c|}{ Quality-adjusted life years } \\
\hline & & Total & Incremental (\%) & Total & Incremental (\%) & Total & Incremental (\%) \\
\hline \multicolumn{8}{|c|}{ Relative risk of cardiovascular disease mortality } \\
\hline \multirow{2}{*}{$\begin{array}{l}\text { Upper bound of } \\
95 \% \mathrm{Cl}\end{array}$} & No & 2465 & - & 17.29 & - & 15.35 & - \\
\hline & Yes & 3047 & $582(23.6 \%)$ & 16.74 & $-0.55(-3.2 \%)$ & 14.60 & $-0.75(-4.9 \%)$ \\
\hline \multirow{2}{*}{$\begin{array}{l}\text { Lower bound of } \\
95 \% \mathrm{Cl}\end{array}$} & No & 2465 & - & 17.29 & - & 15.35 & - \\
\hline & Yes & 3083 & $618(25.1 \%)$ & 16.79 & $-0.50(-2.9 \%)$ & 14.63 & $-0.72(-4.7 \%)$ \\
\hline \multicolumn{8}{|c|}{ Relative risk of asthma morbidity } \\
\hline \multirow{2}{*}{$\begin{array}{l}\text { Upper bound of } \\
95 \% \mathrm{Cl}\end{array}$} & No & 2465 & - & 17.29 & - & 15.35 & - \\
\hline & Yes & 2869 & $404(16.4 \%)$ & 16.27 & $-1.02(-5.9 \%)$ & 13.66 & $-1.69(-11.0 \%)$ \\
\hline \multirow{2}{*}{$\begin{array}{l}\text { Lower bound of } \\
95 \% \mathrm{Cl}\end{array}$} & No & 2465 & - & 17.29 & - & 15.35 & - \\
\hline & Yes & 3255 & $790(32.0 \%)$ & 17.05 & $-0.24(-1.4 \%)$ & 15.08 & $-0.27(-1.8 \%)$ \\
\hline \multicolumn{8}{|c|}{ Utilities of disease states } \\
\hline \multirow{2}{*}{$\begin{array}{l}\text { Upper bound of } \\
95 \% \mathrm{Cl}\end{array}$} & No & - & - & - & - & 15.62 & - \\
\hline & Yes & - & - & - & - & 15.19 & $-0.43(-2.8 \%)$ \\
\hline \multirow{2}{*}{$\begin{array}{l}\text { Lower bound of } \\
95 \% \mathrm{Cl}\end{array}$} & No & - & - & - & - & 14.91 & - \\
\hline & Yes & - & - & - & - & 13.45 & $-1.46(-9.8 \%)$ \\
\hline \multicolumn{8}{|c|}{ Healthcare costs of disease states } \\
\hline \multirow{2}{*}{$\begin{array}{l}\text { Upper bound of } \\
95 \% \mathrm{Cl}\end{array}$} & No & 3521 & - & - & - & - & - \\
\hline & Yes & 4378 & $857(24.3 \%)$ & - & - & - & - \\
\hline \multirow{2}{*}{$\begin{array}{l}\text { Lower bound of } \\
95 \% \mathrm{Cl}\end{array}$} & No & 1595 & - & - & - & - & - \\
\hline & Yes & 1983 & 388 (24.3\%) & - & - & - & - \\
\hline
\end{tabular}

of the values projected for 5 years, suggesting that the direct healthcare costs associated with SHS exposure have higher impact on the later part of the time horizon). This result was consistent with the sensitivity analyses with different discount rate, where the negative economic impact of SHS exposure increased as the time horizon increased (from $5.7 \%$ to $33.8 \%$, table 3 , figure 2A).

The univariate sensitivity analysis showed that our results were robust across various assumptions except for the relative risk of lung cancer morbidity, which showed that SHS exposure had the highest negative economic impact $(45.9 \%$ increase in direct healthcare expenditure) compared with non-exposed women. The probabilistic sensitivity analyses showed that SHS non-exposed women had similar health outcomes compared with the SHS-exposed women, but their expected healthcare costs vary more widely (see online supplementary figure 1); the healthcare costs and the QALYs for the non-exposed women varied from US\$1880 to US\$3131 (66.6\% variation) and from 14.92 QALYs to 15.67 QALYs (5.0\% variation), respectively. The variation was even higher for the SHS-exposed women, such that the healthcare costs and the QALYs varied from US $\$ 1983$ to US $\$ 4303$ (117.0\% variation) and from 9.43 QALYs to 15.43 QALYs (63.5\% variation), respectively.
Model validation: effect of SHS exposure on lung cancer incidence

We estimated the impact of SHS exposure on health outcomes by incorporating the relative risk of specific diseases with various epidemiologic data. We compared our lung cancer incidence projections among SHS-exposed and non-exposed women with that reported by Jee $e t a l^{25}$ Jee and colleagues reported 12.5 and 4.4 lung cancer per 100000 person year for SHS-exposed and non-exposed women, respectively, which were similar to our study projections (10.12 and 5.16 lung cancer per 100000 person year for SHS-exposed and non-exposed women, respectively).

\section{DISCUSSION}

The SHE model predicted that the SHS-exposed women incurred an additional US\$367 (before discount) or US\$600 (after discount) in their lifetime, and live 3.41 years (before discount) or 0.53 years (after discount) years shorter than their counterparts who were not exposed to SHS. Their QALYs are 3.48 QALYs (before discount) or 0.73 QALYs (after discount) lower than those of women not exposed to SHS. Several studies have estimated the economic impact of SHS exposure; Waters and colleagues analysed the direct healthcare costs related with SHS 

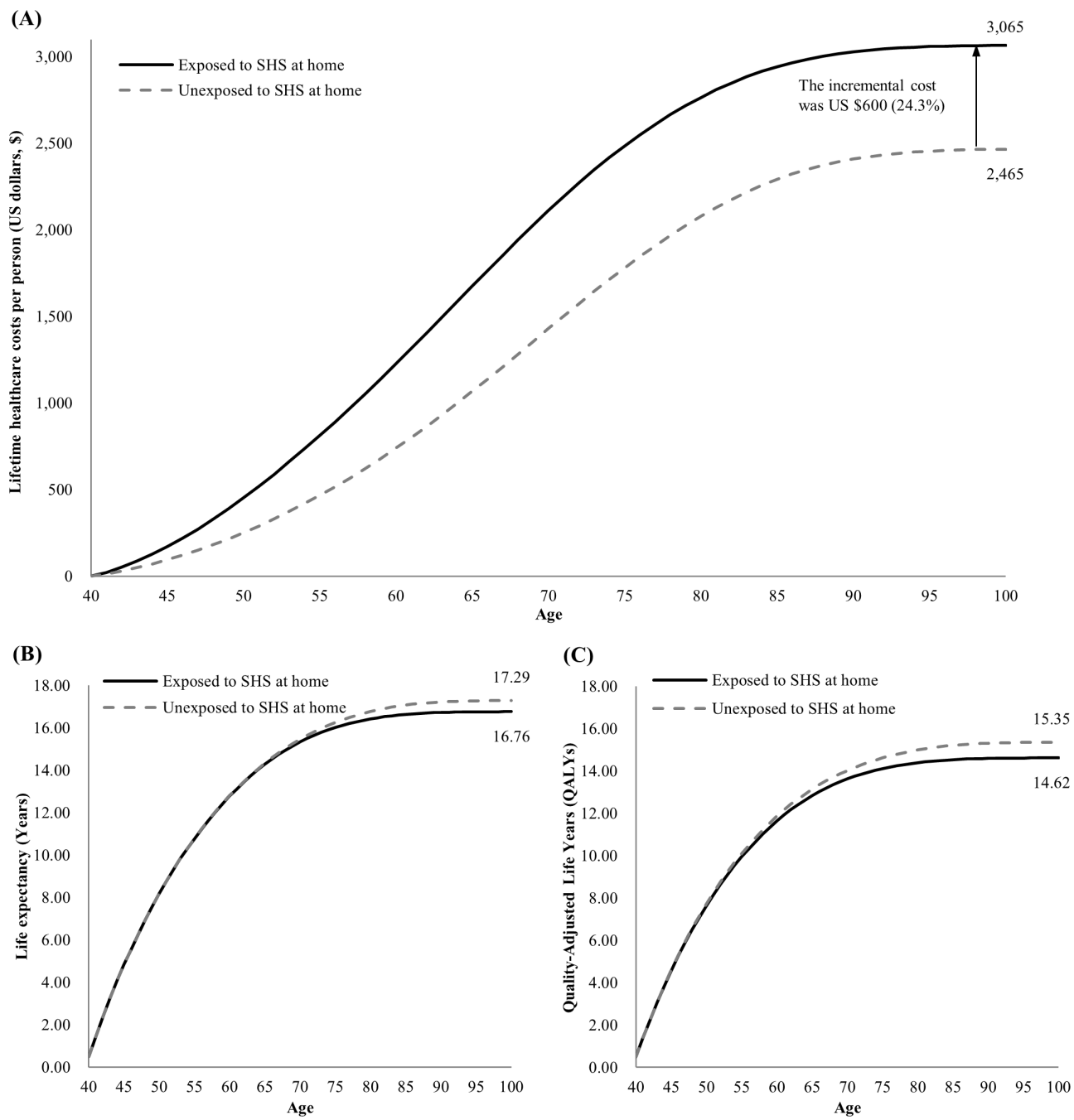

Figure 2 Cumulative lifetime healthcare costs, life expectancy and quality-adjusted life years for Korean adult women who are exposed to secondhand smoke (SHS) at home compared with women not exposed. (A) Lifetime healthcare costs (US dollars); (B) life expectancy (years); (C) quality-adjusted life years (QALYs).

exposure among Minnesota residents, and concluded that SHS exposure is associated with US $\$ 44.58$ (or US $\$ 51.66$ in 2014 , adjusted by the medical care component of CPI) per resident per year. ${ }^{49}$ Max and colleagues reported that SHS was responsible for US\$241 million in healthcare cost and US $\$ 119$ million in lost productivity costs, resulting in US\$213 per non-smoker in California exposed to SHS. ${ }^{4}$ Those studies reported a higher incremental cost compared with ours, which could be attributed to our conservative assumptions, such as excluding children and the loss of the productivity costs, only including health conditions with relative risks that are significantly increased and assuming no utility difference between the SHS exposure status. Also, the healthcare cost in Korea is generally lower than that in the USA, thanks to Korea's National Health Insurance system. Thus, our healthcare cost estimate could actually underestimate the effect of the SHS exposure. Our estimate could refer to the lower bound of the healthcare costs associated with SHS exposure. Based on Korean national survey in 2014, about $13.9 \%$ of non-smoking adult women are exposed to SHS at home. ${ }^{50}$ It has been reported that about 13.9 million Korean women are aged 40 or older as of January 2016, thus about 1.9 million adult Korean women are estimated to be exposed to the SHS exposure at home, which translates into US $\$ 1.16$ billion ( 1.9 million $\times$ incremental medical cost due to SHS exposure (600 incremental USD per person exposed to SHS)) at national level.

Our analysis suggested that higher health expenditures and lower QALYs/life expectancy are expected for the SHS exposed women and the negative health effect of SHS exposure was greater on quality of life compared with that on life expectancy, regardless of various assumptions. In other words, SHS exposure was more closely associated with morbidity than mortality; thus, the SHS-exposed women might suffer more in terms of quality of life compared with quantity of life. Since the diseases caused by SHS exposure are likely to be of chronic nature but not of high mortality (such as asthma or MI), the exposed women are likely to chronically suffer from diseases caused by SHS exposure, thus their quality of life decreased, while their life expectancy is similar to 
that of the non-exposed. Thus, it is not surprising that we reached such conclusions.

Our analysis indicated that the negative impact of SHS exposure on health outcome could be underestimated if life expectancy was solely used as a health outcome measure. Given the negative economic and health impact of SHS exposure at home, more aggressive smoking ban policies at home or more education for household members about the importance of SHS exposure should be considered.

Also, the SHE model illustrated that SHS exposure-attributable health costs have higher impact on older adults (eg, in their 70s) who had been exposed to the SHS for longer period than earlier (eg, in their 50s), implying that the impact of SHS exposure is aggravated for older age group, thus aggressive smoking bans or education on SHS at home as early as possible might be needed for those women who married current smokers, even though individuals in those age groups may not suffer from premature deaths.

Few studies have projected the impact of SHS exposure on quality of life. To our knowledge, our model is the first attempt to include QALYs in projecting health outcomes attributable to SHS exposure. Compared with previous studies, our Markov model has enhanced features because it has a lifetime horizon, incorporates QALYs and allows subjects to move between specific health states. ${ }^{15}$

The model-based approach has several strengths; it enables analysts to extrapolate beyond the observed timeline and geographic settings and synthesise data from multiple sources. ${ }^{21}{ }^{24}$ However, our results should be cautiously interpreted, since it hinges on several assumptions. First, the SHE model included four health conditions that demonstrated SHS exposure is associated with increased risk at a statistically significant level, but other conditions such as breast cancer, cervical cancer and COPD have been shown to be associated with the SHS exposure, yet with conflicting results. ${ }^{25} 3233 \mathrm{We}$ excluded those conditions to reach more conservative conclusion, yet we could have underestimated the impact of SHS exposure.

Second, we only focused on SHS exposure, and thirdhand smoke (THS) exposure has been not considered in our analysis. THS exposure occurs when non-smokers are exposed to the residuals of nicotine or other chemicals on indoor surfaces caused by the tobacco smoke. Although THS exposure also could be associated with the negative impact of tobacco smoke, few studies have quantified the increased risk attributable to THS. Therefore, our study could not include the impact of THS.

In addition, our study was based on the current reported SHS exposure and did not consider SHS occurred in the past. Since most of the epidemiological studies we quoted considered spousal current smoking status and ignored whether those women had been exposed to the SHS in the past, it acts as a limitation.

Finally, although children and infants that reside with current smokers suffer from significant health burdens such as sudden infant death syndrome or various respiratory diseases, ${ }^{51}{ }^{52}$ those populations were not included in our model. Given that children and infants are vulnerable to their parents' smoking behaviour, further study is needed to estimate the impact of SHS on children and infants and to provide policy recommendations on these populations.

\section{CONCLUSION}

Although SHS exposure marginally decreased the life expectancy of exposed women, its negative impacts on quality of life and costs are substantial, and the result was consistent across a wide range of assumptions. Life expectancy might underestimate the impact of SHS exposure on health outcomes, especially if the time horizon of the analysis is not long enough. Early interventions for smoking behaviour could especially reduce avoidable healthcare costs.

Contributors All authors participated in the design of the study. ARH and JL conducted systematic review of cost, utility and epidemiology data. JL and SJB built Markov simulation model and interpreted data. SJB, JL and K-ML generated the manuscript, and DC critically edited and commented on the manuscript. All authors read and approved the final manuscript.

Funding This research was supported by the Basic Science Research Program through the National Research Foundation of Korea (NRF) funded by the Ministry of Education (2014R1A1A2058657).

Competing interests None declared.

Provenance and peer review Not commissioned; externally peer reviewed. Data sharing statement No additional data available.

Open Access This is an Open Access article distributed in accordance with the Creative Commons Attribution Non Commercial (CC BY-NC 4.0) license, which permits others to distribute, remix, adapt, build upon this work non-commercially, and license their derivative works on different terms, provided the original work is properly cited and the use is non-commercial. See: http://creativecommons.org/ licenses/by-nc/4.0/

(C) Article author(s) (or their employer(s) unless otherwise stated in the text of the article) 2017. All rights reserved. No commercial use is permitted unless otherwise expressly granted.

\section{REFERENCES}

1. OECD Indicators. Health at a Glance, 2015.

2. World Health Organization. Tobacco Fact Sheet No 339. 2015. http://www.who.int/mediacentre/factsheets/fs339/en/. (accessed 3.27.2015).

3. Plescia M, Wansink D, Waters HR, et al. Medical costs of secondhand-smoke exposure in North Carolina. N C Med J 2011;72:7-12.

4. Max W, Sung HY, Shi Y. The cost of secondhand smoke exposure at home in California. Tob Control 2015;24:205-10.

5. Eisner MD, Katz PP, Yelin EH, et al. Measurement of environmental tobacco smoke exposure among adults with asthma. Environ Health Perspect 2001;109:809-14.

6. Riboli E, Preston-Martin S, Saracci R, et al. Exposure of nonsmoking women to environmental tobacco smoke: a 10-country collaborative study. Cancer Causes Control 1990;1:243-52.

7. Oberg M, Jaakkola MS, Woodward A, et al. Worldwide burden of disease from exposure to second-hand smoke: a retrospective analysis of data from 192 countries. Lancet 2011;377:139-46.

8. World Health Organization. International Agency for Research on Cancer. Tobacco smoke and involuntary smoking: IARC, 2004.

9. US Department of Health and Human Services. The health consequences of involuntary exposure to tobacco smoke: a report of the Surgeon General. 709. Atlanta, GA: US Department of Health and Human Services, Centers for Disease Control and Prevention, Coordinating Center for Health Promotion, National Center for 
Chronic Disease Prevention and Health Promotion, Office on Smoking and Health, 2006.

10. McGhee SM, Ho LM, Lapsley HM, et al. Cost of tobacco-related diseases, including passive smoking, in Hong Kong. Tob Control 2006;15:125-30.

11. Barendregt JJ, Bonneux L, van der Maas PJ. The health care costs of smoking. N Engl J Med 1997;337:1052-7.

12. Orme ME, Hogue SL, Kennedy LM, et al. Development of the health and economic consequences of smoking interactive model. Tob Control 2001;10:55-61.

13. Rasmussen SR, Prescott E, Sørensen TI, et al. The total lifetime health cost savings of smoking cessation to society. Eur J Public Health 2005;15:601-6.

14. Godfrey C, Ali S, Parrott S, et al; Economics Model of adult smoking related costs and consequences for England, 2011.

15. Howard P, Knight C, Boler A, et al. Cost-Utility analysis of Varenicline versus existing Smoking Cessation strategies using the BENESCO Simulation Model. Pharmacoeconomics 2008;26:497-511.

16. Tran K, Asakawa K, Cimon K, et al. Pharmacologic-based strategies for smoking cessation: clinical and cost-effectiveness analyses. CADTH Technol Overv 2012;2.

17. Thun M, Henley J, Apicella L. Epidemiologic studies of fatal and nonfatal cardiovascular disease and ETS exposure from spousal smoking. Environ Health Perspect 1999;107(Suppl 6):841-6.

18. Eisner MD, Balmes J, Katz PP, et al. Lifetime environmental tobacco smoke exposure and the risk of chronic obstructive pulmonary disease. Environ Health 2005;4:7.

19. Meltzer D, Johannesson M. Inconsistencies in the "societal perspective" on costs of the Panel on Cost-Effectiveness in Health and Medicine. Med Decis Making 1999;19:371-7.

20. Weinstein MC, et al. Recommendations of the panel on CostEffectiveness in Health and Medicine. JAMA: The Journal of the American Medical Association 1996;276:1253-8.

21. Weinstein MC, O'Brien B, Hornberger J, et al. Principles of good practice for decision analytic modeling in health-care evaluation: report of the ISPOR Task Force on Good Research Practices-modeling studies. Value Health 2003;6:9-17.

22. Bae S, Lee S, Bae EY, et al. Korean guidelines for pharmacoeconomic evaluation (Second and updated version). Pharmacoeconomics 2013;31:257-67.

23. Beck JR, Pauker SG. The Markov process in medical prognosis. Med Decis Making 1983;3:419-58.

24. Siebert U, Alagoz O, Bayoumi AM, et al. State-transition modeling: a report of the ISPOR-SMDM Modeling Good Research Practices Task Force--3. Value Health 2012:15:812-20.

25. Jee SH, Ohrr H, Kim IS. Effects of husbands' smoking on the incidence of lung Cancer in Korean women. Int $J$ Epidemiol 1999;28:824-8

26. Jaakkola MS, Piipari R, Jaakkola N, et al. Environmental tobacco smoke and adult-onset asthma: a population-based incident casecontrol study. Am J Public Health 2003;93:2055-60.

27. Lee PN, Forey BA. Environmental tobacco smoke exposure and risk of stroke in nonsmokers: a review with meta-analysis. J Stroke Cerebrovasc Dis 2006;15:190-201.

28. Taylor R, Najafi F, Dobson A. Meta-analysis of studies of passive smoking and lung Cancer: effects of study type and continent. Int $J$ Epidemiol 2007;36:1048-59.

29. Albers AB, Biener L, Siegel $M$, et al. Household smoking bans and adolescent antismoking attitudes and smoking initiation: findings from a longitudinal study of a Massachusetts youth cohort. Am J Public Health 2008;98:1886-93.

30. Öberg M, Jaakkola MS, Prüss-Üstün A, et al; Second-hand smoke: assessing the burden of disease at national and local levels: World Health Organization, 2010.
31. Oono IP, Mackay DF, Pell JP. Meta-analysis of the association between secondhand smoke exposure and stroke. J Public Health 2011;33:496-502.

32. Kim WJ, Song JS, Park DW, et al. The effects of secondhand smoke on chronic obstructive pulmonary disease in nonsmoking Korean adults. Korean J Intern Med 2014;29:613-9.

33. Johnson KC. Accumulating evidence on passive and active smoking and breast Cancer risk. Int J Cancer 2005;117:619-28.

34. Kim SY, Kim SG, Park JH, et al. [Costs of initial Cancer care and its affecting factors]. J Prev Med Public Health 2009;42:243-50.

35. Health Insurance Review and Assessment Service. Clinical and economic evaluation of statin medications in Korea, 2009.

36. Ward S, Lloyd Jones M, Pandor A, et al. A systematic review and economic evaluation of statins for the prevention of coronary events. Health Technol Assess 2007;11:178.

37. Ministry of Health, Welfare and Family Affairs. Korea Health Statistics 2014: Korea National Health and Nutrition Examination Survey (KNHANES VI-2), 2015.

38. Health Insurance Review and Assessment Service. Construction of National Surveillance System for Cardiovascular and cerebrovascular disease. 2006.

39. Ministry of Health, Welfare and Family Affairs. Cancer Registration Statistics. http://kosis.kr/statHtml/statHtml.do?orgld=117\&tblld=DT_ 117N_A0024\&conn_path=I3 (accessed January, 26 2016).

40. Statistics Korea. Cause of Death Statistics. http://kosis.kr/statHtml/ statHtml.do?orgld=101\&tblld=DT_1B34E01\&conn_path=13 (accessed January, 26 2016).

41. Winer RA, Qin X, Harrington T, et al. Asthma incidence among children and adults: findings from the behavioral risk factor surveillance system asthma call-back survey--United States, 20062008. J Asthma 2012;49:16-22.

42. Park CS, Kang HY, Kwon I, et al. [Cost-of-illness study of asthma in Korea: estimated from the Korea National Health insurance claims database]. J Prev Med Public Health 2006;39:397-403.

43. Jacobs P, Ohinmaa A, Brady B. Providing systematic guidance in pharmacoeconomic guidelines for analysing costs. Pharmacoeconomics 2005;23:143-53.

44. Statistics Korea. Consumer Price survey(Index). http://kosis.kr/ statHtml/statHtml.do?orgld=101\&tblld=DT_1JOA001\&conn_path=I3 (accessed January, 26 2016)

45. Seoul Money Brokerage. Basic Exchange Rate Seoul. http://www. smbs.biz/Eng/ExRate/StdExRate.jsp (accessed January, 26 2016).

46. Kang EJ, Ko SK. A catalogue of EQ-5D utility weights for chronic diseases among noninstitutionalized community residents in Korea. Value Health 2009:12 Suppl 3:S114-7.

47. Trippoli S, Vaiani M, Lucioni C, et al. Quality of Life and Utility in patients with Non-Small Cell lung Cancer. Pharmacoeconomics 2001:19:855-63.

48. Briggs $\mathrm{AH}$. Handling uncertainty in cost-effectiveness models. Pharmacoeconomics 2000;17:479-500.

49. Waters HR, Foldes SS, Alesci NL, et al. The economic impact of exposure to secondhand smoke in Minnesota. Am J Public Health 2009;99:754-9.

50. Korean Ministry of Health and Welfare. Korea Health Statistics 2014: Korea National Health and Nutrition Examination Survey (KNHANES VI-2), 2015

51. Anderson HR, Cook DG. Passive smoking and sudden infant death syndrome: review of the epidemiological evidence. Thorax 1997;52:1003-9.

52. Windham GC, Eaton A, Hopkins B. Evidence for an association between environmental tobacco smoke exposure and birthweight: a meta-analysis and new data. Paediatr Perinat Epidemiol 1999;13:35-57. 